Vinko Škafar

\title{
Trije govori papeža Frančiška med njegovim nedavnim romanjem na Madžarsko in Slovaško
}

Three Speeches of Pope Francis Delivered During

His Recent Pilgrimage to Hungary and Slovakia

\section{Papež Frančišek se je na Madžarskem in Slovaškem srečal z nekatoliškimi kristjani in J/judi}

Papež Frančišek je v nedeljo, 12. septembra 2021, obiskal Madžarsko in še istega dne Slovaško, kjer je ostal tri dni. V obeh državah se je srečal s predstavniki nekatoliških kristjanov in s predstavnikom judovske skupnosti. Prinašamo tri papeževe govore na teh srečanjih.

\section{Govor papeža Frančiška v Budimpešti ob srečanju s predstavniki nekatoliških Cerkva in judovske skupnosti (12.9. 2021)}

Papež Frančišek se je v Budimpešti srečal s predstavniki Ekumenskega sveta Cerkva in nekaterih judovskih skupnosti na Madžarskem. V svojem govoru je izpostavil, da Bog naših očetov vedno odpira nove poti: kot je puščavo spremenil v pot proti obljubljeni deželi, tako nas želi popeljati iz suhih puščav sovraštva in brezbrižnosti v tako želeno domovino občestva. Od nas se zahteva, da pustimo za seboj nesporazume iz preteklosti 
in domišljavost, da imamo prav in krivimo druge, ter se odpravimo proti njegovi obljubi miru.

Papež je pozval k skupnemu prizadevanju za vzgojo za bratstvo, da sovraštvo ne bi prevladalo, pri čemer je posebej opozoril na nevarnost antisemitizma, ki se še vedno širi. Kot je dejal, Bog zaveze od nas zahteva, da ne podležemo logiki osamitve in delnih interesov. Ne želi zavezništev z nekaterimi na račun drugih, ampak želi osebe in skupnosti, ki so mostovi občestva z vsemi.

Predstavniki večinskih verstev imajo na Madžarskem nalogo, da ustvarijo pogoje za spoštovanje in spodbujanje verske svobode za vse. So zgled, zato da nihče ne bi mogel reči, da iz ust Božjih mož prihajajo razdiralne besede, ampak le sporočila odprtosti in miru. V svetu, ki ga razdvajajo številni konflikti, je to najboljše pričevanje tistih, ki so prejeli milost, da poznajo Boga zaveze in miru.

Papeža sta najprej nagovorila kalvinski škof József Steinbach in rabin Zoltán Radnóti, ki je prebral govor glavnega madžarskega rabina Róberta Fröhlicha.

\section{Dragi bratje!}

Vesel sem, da sem vas srečal. Vaše besede, za katere se vam zahvaljujem, in vaša navzočnost drug ob drugem izražajo veliko željo po edinosti. Pripovedujejo o poti, ki je včasih strma, včasih naporna, a se je lotevate s pogumom in dobro voljo ter se med seboj podpirate pod pogledom Najvišjega, ki blagoslavlja brate in sestre, ki živijo skupaj (prim. Ps 133,1).

Vidim vas, bratje v veri v Kristusa, in blagoslavljam pot občestva, po kateri hodite. V mislih sem usmerjen v opatijo Pannonhalma, živo duhovno središče te države, kjer ste se pred tremi meseci srečali, da bi skupaj razmišljali in molili. Skupaj moliti drug za drugega in v ljubezni delati drug z drugim za ta svet, ki ga Bog tako ljubi (prim. Jn 3,16): to je najbolj konkretna pot k popolni edinosti. 
Vidim vas, brate po veri našega očeta Abrahama. Zelo cenim vašo zavzetost, o kateri ste pričevali in s katero rušite zidove ločevanja iz preteklosti; Judje in kristjani $v$ drugem ne želite več videti tujca, ampak prijatelja; ne več nasprotnika, ampak brata. To je od Boga blagoslovljena sprememba pogleda, spreobrnjenje, ki odpira nove začetke, očiščenje, ki obnavlja življenje. Slovesna praznika roš hašana in jom kipur, ki sta $v$ tem času in ob katerih vam voščim vse dobro, sta milostni priložnosti za obnovitev spoštovanja teh duhovnih pozivov. Bog naših očetov vedno odpira nove poti: kot je puščavo spremenil v pot proti obljubljeni deželi, tako nas želi popeljati iz suhih puščav sovraštva in brezbrižnosti v tako želeno domovino občestva.

Ni naključje, da morajo tisti, ki so v Svetem pismu poklicani, da na poseben način sledijo Gospodu, vedno iti ven, hoditi, doseči neraziskane dežele in še neznane prostore. Pomislimo na Abrahama, ki je zapustil dom, sorodstvo in domovino. Kdor sledi Bogu, je poklican, da odide. Od nas se zahteva, da pustimo za seboj nesporazume iz preteklosti in domišljavost, da imamo prav in krivimo druge, ter se odpravimo proti njegovi obljubi miru, kajti Bog ima vedno načrte miru, nikoli nesreče (prim. Jer 29,11).

Z vami bi se rad dotaknil sugestivne podobe Verižnega mostu, ki povezuje dva dela tega mesta: ne staplja ju, ampak ju drži povezana. Takšne morajo biti vezi med nami. Kadarkoli je obstajala skušnjava, da bi se drugega absorbiralo, se ni gradilo, temveč uničevalo; podobno je bilo, ko se ga je hotelo getoizirati namesto integrirati. Kolikokrat v zgodovini se je to že zgodilo! Biti moramo budni in moliti, da se to ne bi ponovilo. In se skupaj zavzemati za vzgojo za bratstvo, da prekipevanje sovraštva, ki ga želi uničiti, ne bi prevladalo. Mislim na grožnjo antisemitizma, ki se še vedno širi v Evropi in drugod. To je zažigalna vrvica, ki jo je treba ugasniti. Najboljši način, da ga dezaktiviramo, pa je skupaj pozitivno delovati in spodbujati bratstvo. Most nas ponovno poučuje: podpirajo ga velike verige, sestavljene iz številnih členov. Mi smo ti členi in vsak člen je temeljnega pomena: zato ne moremo več živeti v sumničenju in nevednosti, oddaljeni in nesoglasni. 
Most povezuje dve strani. V tem smislu spominja na pojem zaveze, ki je v Svetem pismu temeljnega pomena. Bog zaveze od nas zahteva, da ne podležemo logiki osamitve in delnih interesov. Ne želi zavezništev z nekaterimi na račun drugih, ampak želi osebe in skupnosti, ki so mostovi občestva z vsemi. V tej državi imate vi, ki predstavljate večinska verstva, nalogo, da ustvarite pogoje za spoštovanje in spodbujanje verske svobode za vse. Imate zgledno vlogo pred vsemi: zato da nihče ne bi mogel reči, da iz ust Božjih mož prihajajo razdiralne besede, ampak le sporočila odprtosti in miru. V svetu, ki ga razdvajajo številni konflikti, je to najboljše pričevanje tistih, ki so prejeli milost, da poznajo Boga zaveze in miru.

Verižni most ni le najbolj znan, ampak tudi najstarejši most v mestu. Številne generacije so ga prečkale. Vabi nas, da se spomnimo preteklosti. Našli bomo trpljenje in temo, nerazumevanje in preganjanje, a če bomo šli h koreninam, bomo odkrili še večjo skupno duhovno dediščino. Ta zaklad nam omogoča, da skupaj gradimo drugačno prihodnost. $Z$ veliko ganjenostjo mislim tudi na mnoge Božje prijatelje, ki so izžarevali njegovo luč v nočeh sveta. Med mnogimi omenjam velikega pesnika te dežele, Miklósa Radnótija, čigar bleščečo kariero je prekinilo slepo sovraštvo tistih, ki so mu samo zato, ker je bil judovskega rodu, najprej preprečili poučevanje, nato pa ga odtrgali od družine.

Zaprt $v$ koncentracijskem taborišču, $v$ najtemnejšem in najbolj pokvarjenem breznu človeštva, je vse do smrti pisal poezijo. Njegova pesniška zbirka Borova beležnica je edina pesniška zbirka, ki je preživela holokavst: priča o moči verovanja v toplino ljubezni sredi mraza taborišča in o luči vere, ki osvetljuje temo sovraštva.

Avtor, ki so ga dušile verige, ki so mu stiskale dušo, je v višji svobodi našel pogum in zapisal: »Kot zapornik sem si vzel mero za vsako upanje« (Borova beležnica, Pismo ženi). In je zastavil vprašanje, ki odmeva danes tudi za nas: »In ti, kako živiš? Ali tvoj glas najde odmev v tem času? (Borova beležnica, Prva ekloga) Naši glasovi, dragi bratje, ne morejo ne biti odmev tiste Besede, ki nam jo je dalo nebo, odmev upanja in miru. Tudi če nismo slišani ali smo 
napačno razumljeni, z dejanji nikoli ne zanikajmo Razodetja, ki smo mu priča.

Nazadnje je Radnóti v zapuščeni samoti koncentracijskega taborišča, ko se je začel zavedati, da življenje usiha, zapisal: »Tudi jaz sem zdaj korenina [...] bil sem cvet, postal sem korenina" (Borova beležnica, Korenina). Tudi mi smo poklicani, da postanemo korenine. Pogosto iščemo sadove, rezultate, potrditve. Toda On, ki svoji Besedi daje sadove na zemlji z enako nežnostjo kot dež, da vzklije polje (prim. Iz 55,10), nas spominja, da so naše poti vere semena: semena, ki se spremenijo v podzemne korenine, korenine, ki hranijo spomin in omogočajo, da vzklije prihodnost. To od nas zahteva Bog naših očetov, kajti - kot je zapisal neki drugi pesnik - »Bog čaka nekje drugje, čaka ravno na dnu vsega. Spodaj. Kjer so korenine."(R. M. Rilke, Vladimir, slikar oblakov) Vrh lahko dosežemo, samo če smo globoko ukoreninjeni. Ukoreninjeni v poslušanju Najvišjega in drugih bomo pomagali našim sodobnikom, da se sprejmejo in ljubijo. Samo če bomo korenine miru in poganjki edinosti, bomo verodostojni v očeh sveta, ki nas gleda s hrepenenjem po razcvetu upanja. Hvala in srečno skupno pot!

Prevod: Andreja Červek, Radio Vatikan

\section{Govor papeža Frančiška na ekumenskem srečanju Cerkva in cerkvenih skupnosti v Bratislavi (12.9. 2021)}

Prvo srečanje po prihodu v Bratislavo je imel papež Frančišek z Ekumenskim svetom Cerkva na Slovaškem v apostolski nunciaturi.

Dragi člani Ekumenskega sveta Cerkva v Republiki Slovaški!

Iz srca vas pozdravljam ter se vam zahvaljujem, da ste sprejeli povabilo in mi prišli naproti. Jaz sem kot romar na Slovaškem, vi pa kot dragi gostje na nunciaturi. Zadovoljen sem, da je prvo moje srečanje z vami. Gre za znamenje, da krščanska vera je in tudi hoče biti v tej državi poganjek edinosti in kvas bratstva. Hvala blaženosti, bratu Rastislavu za Vašo navzočnost; hvala, dragi škof Ivan, 
predsednik Ekumenskega sveta, za besede, ki si mi jih namenil, saj pričujejo o prizadevanju za hotenje po nadaljevanju skupne poti v prehodu iz spora v občestvo.

Pot vaših skupnosti se je ponovno začela po letih ateističnega preganjanja, ko so versko svobodo preprečevali ali pa postavljali na trdo preizkušnjo. Potem pa je končno prišla. Zdaj pa vam je skupen odsek poti, na katerem okušate, kako je lepo, a istočasno težko živeti vero kot svoboden človek. Pojavlja se namreč skušnjava po vrnitvi v suženjstvo, tokrat ne nekega režima, temveč v še hujše suženjstvo, in to je notranje.

In to je tisto, pred čimer je svaril Dostojevski v svoji znani pripovedi Legenda o velikem inkvizitorju. Jezus se je vrnil na zemljo in so ga zaprli. Inkvizitor mu nameni ostre besede obsodbe, da je dal preveliko pomembnost svobodi ljudi. Pravi mu: „Ti hočeš iti v svet in greš tja s praznimi rokami, a z obljubo o svobodi, ki si je oni v svoji preprostosti in v svojem prirojenem neredu ne morejo niti zamisliti, se je pa bojijo in jih je groza, saj za človeka še nič ni bilo tako neznosnega, kot je za človeka svoboda!" (Bratje Karamazovi) In da bo mera polna, še doda, da so ljudje pripravljeni zamenjati svojo svobodo za bolj udobno suženjstvo, torej podvrženost nekomu, ki namesto njih odloča, čeprav imajo kruh in varnost. In tako očita Jezusu, da ni hotel postati cesar in ukloniti vesti ljudi, da bi z močjo vzpostavil mir. Namesto tega je imel za človeka rajši svobodo, medtem ko ljudje zahtevajo kruh in še nekaj malega drugega.

Dragi bratje, naj nas to ne doleti. Pomagajmo si, da ne bomo padli v zanko biti zadovoljni s kruhom in še nekaj malega drugega. Kajti to tveganje pride, ko se stvari uredijo, ko se ustalimo in se prepustimo ohranjanju mirnega življenja. Tedaj to, kar se želi doseči, ni več svoboda, ki jo imamo v Jezusu Kristusu (Gal 2,4), njegova resnica, ki nas osvobaja (prim. Jn 8,32), temveč ohranjanje mest in privilegijev, kar je po evangeliju »kruh in še malo drugega«. Tukaj, v osrčju Evrope, si postavimo vprašanje: Smo kristjani malo izgubili gorečnost oznanjevanja in preroškost pričevanja? Nas osvobaja resnica evangelija ali pa se čutimo svobodne, ko dosežemo comfort zone (varnost znanega), ki nam omogoči voditi same sebe in iti 
naprej brez posebnih posledic? In še, če se zadovoljimo s kruhom in varnostjo, smo morda izgubili zagon za iskanje edinosti, za katero je prosil Jezus, edinosti, ki prav gotovo zahteva zrelo svobodo za pomembne odločitve, odpovedi in žrtve, saj je premisa, da bo svet veroval (prim. Jn 17,21)? Ne zanimajmo se samo za to, kar lahko koristi našim posameznim skupnostim, saj je svoboda brata in sestre tudi naša svoboda, kajti naša svoboda ni popolna brez njega in brez nje.

Tukaj se je evangelizacija zgodila na bratski način, saj ima vtisnjen pečat svetih solunskih bratov Cirila in Metoda. Onadva, ki sta bila priči, sta še vedno enotna in osredotočena na gorečnost oznanila, da nam bosta pomagala nadaljevati pot ter gojiti bratsko občestvo med nami v Jezusovem imenu.

\section{Govor papeža Frančiška na srečanju z judovsko skupnostjo v Bratislavi na Trgu Rybné námestie (13.9. 2021)}

Papež je slovaškim J/judom spregovoril o mirnem sobivanju J/judov in kristjanov v preteklosti ter poudaril pomen spomina, ki ga je po njegovih besedah treba tudi prečistiti. Jude na Slovaškem je povabil, naj še naprej gojijo poklicanost, da so znamenje blagoslova za vse rodove zemlje.

\section{Kraj, blagoslovljen zaradi bratstva v imenu Najvišjega}

Dragi bratje in sestre, dober večer!

Zahvaljujem se vam za vaše besede dobrodošlice in za vaši pričevanji, ki ste nam ju podarili. Tukaj sem kot romar, da bi se dotaknil tega kraja ter da bi se ta kraj dotaknil mene. Trg, na katerem smo, je za vašo skupnost zelo pomenljiv. Ohranja živ spomin na bogato preteklost: stoletja je bil del judovske četrti; tukaj je deloval znani rabin Chatam Sofer. Tukaj je bila sinagoga, prav poleg katedrale Kronanja. Kakor je bilo rečeno, je arhitektura izražala mirno sobivanje dveh skupnosti; bila je redek in izredno zgovoren simbol, čudovito znamenje edinosti v imenu Boga naših očetov. Tukaj tudi jaz, kakor mnogi izmed njih, čutim potrebo, da si »sezujem 
sandale«, saj sem na kraju, ki je blagoslovljen zaradi bratstva ljudi v imenu Najvišjega.

\section{Ime Boga onečaščeno v norosti sovraštva med vojno}

Nato pa je bilo ime Boga onečaščeno: v blaznosti sovraštva je bilo med drugo svetovno vojno umorjenih več kot 100.000 slovaških judov. In ko so se kasneje sledi skupnosti želele izbrisati, je bila tukaj sinagoga porušena. Pisano je: "Ne izgovarjaj v prazno imena Gospodovega.«(2 Mz 20,7) Ime Boga, tj. njegova osebna resničnost, se izgovarja $\mathrm{v}$ prazno, kadar se oskruni edinstveno in neponovljivo dostojanstvo človeka, ki je ustvarjen po njegovi podobi. Tukaj je bilo ime Boga onečaščeno, saj je najhujše možno bogokletje to, da se to ime uporabi za lastne namene, ne pa za to, da bi spoštovali in ljubili druge. Tukaj, pred zgodovino judovskega ljudstva, ki je zaznamovana s to tragično in neizmerno žalitvijo, nas je sram priznati: kolikokrat je bilo neizrekljivo ime Najvišjega uporabljeno za nezaslišana nečloveška dejanja. Koliko zatiralcev je izjavljalo: »Bog je z nami, « vendar pa so bili oni tisti, ki niso bili z Bogom.

\section{Vaša zgodovina je naša zgodovina}

Dragi bratje in sestre, vaša zgodovina je naša zgodovina, vaše bolečine so naše bolečine. Za nekatere izmed vas je spomenik žrtvam holokavsta edini kraj, kjer lahko počastite spomin na svoje drage. Tudi jaz se vam pridružujem. Na spomeniku je v hebrejščini zapisano "Zachor": »Spominjaj se! Spomin ne more in ne sme dati prostora pozabi, saj ne bo dolgotrajne zarje bratstva, ne da bi prej podelili in razgnali temino noči. Tudi za nas odmeva prerokovo vprašanje: »Stražar, kako dolga je še noč?« To je za nas čas, v katerem se ne sme več očrniti podoba Boga, ki blesti v človeku. Pomagajmo si pri tem. Tudi danes namreč ne manjka praznih in lažnih malikov, ki skrunijo ime Najvišjega. To so maliki oblasti in denarja, ki prevladata nad človekovim dostojanstvom; ravnodušnosti, ki obrne pogled na drugo stran; manipulacije, ki instrumentalizirajo religijo tako, da postane vprašanje prevlade, ali pa jo zreducirajo na nekaj nepomembnega. Maliki so prav tako pozaba preteklosti, nepoznavanje, ki vse upraviči, jeza in sovraštvo. 
Povezani smo - to poudarjam - pri obsojanju vsakršnega nasilja, vsakršne oblike antisemitizma ter v prizadevanju za to, da Božja podoba v človeškem bitju ne bi bila oskrunjena.

\section{Trg je tudi kraj, kjer sije luč upanja}

Vendar pa je ta trg, dragi bratje in sestre, tudi kraj, kjer sije luč upanja. Sem vsako leto pridete, da prižgete prvo svečo na svečniku za hanuko. Tako se v temi pokaže sporočilo, da zadnje besede nimata smrt in uničenje, ampak prenova in življenje. In če je bila sinagoga na tem kraju porušena, je skupnost še vedno prisotna. Živa je in odprta za dialog. Tukaj se naši zgodovini ponovno srečata. Tukaj skupaj pred Bogom odločno izražamo pripravljenost, da nadaljujemo po poti približevanja in prijateljstva.

\section{Nadaljevati po bratski poti prečiščevanja spomina}

V zvezi s tem v sebi ohranjam živ spomin na srečanje s predstavniki vaših judovskih in krščanskih skupnosti v Rimu leta 2017. Vesel sem, da je bila zatem ustanovljena Komisija za dialog s Katoliško cerkvijo in da ste skupaj objavili pomembne dokumente. Dobro je podeliti in posredovati to, kar nas združuje. In dobro je nadaljevati, $v$ resnici in iskrenosti, po bratski poti prečiščevanja spomina, da bi ozdravili pretekle rane, pa tudi da bi se spominjali dobrega, ki smo ga prejeli in podarili. Talmud pravi, da kdor uniči enega samega človeka, uniči ves svet, in kdor reši enega samega človeka, reši ves svet. Vsakdo šteje, in veliko šteje to, kar delate s svojo dragoceno podelitvijo. Zahvaljujem se vam za vrata, ki ste jih odprli z obeh strani.

\section{Biti znamenje blagoslova za vse rodove zemlje}

Svet potrebuje odprta vrata. So znamenja blagoslova za človeštvo. Bog je očetu Abrahamu rekel: »V tebi bodo blagoslovljeni vsi rodovi na zemlji.« (1 Mz 12,3) To je odpev, ki narekuje življenja očetov (prim. 1 Mz 18,18; 22,18; 26,4). Jakobu, to je Izraelu, je Bog rekel: "Tvojega zaroda bo kakor peska zemlje. Razširil se boš proti zahodu in vzhodu, proti severu in jugu, in vsi rodovi zemlje bodo 
blagoslovljeni v tebi in v tvojem zarodu.« (1 Mz 28,14) Tukaj, na tej slovaški zemlji, zemlji srečanja med v/Vzhodom in z/Zahodom, naj družina Izraelovih sinov še naprej goji to poklicanost, poziv, da bi bili znamenje blagoslova za vse rodove zemlje. Blagoslov Najvišjega se izliva na nas, ko vidi rod bratov, ki se spoštujejo, se ljubijo in sodelujejo. Naj vas Vsemogočni blagoslovi, da boste mogli biti sredi tolikih sporov, ki onesnažujejo naš svet, vedno, skupaj, priče miru. Šalom!

Prevod: S. Leonida Zamuda, SL 